\title{
La conversación civil
}




\title{
CLÁSICOS HISPÁNICOS \\ Nueva época, no ${ }^{\circ} 16$
}

\author{
Directores: \\ Abraham Madroñal (Université de Genève / CSIC, Madrid) \\ Antonio Sánchez Jiménez (Université de Neuchâtel) \\ Consejo cientifico: \\ Fausta Antonucci (Università di Roma Tre) \\ Anne Cayuela (Université de Grenoble) \\ Santiago Fernández Mosquera (Universidad de Santiago de Compostela) \\ Teresa Ferrer (Universidad de Valencia) \\ Robert Folger (Universität Heidelberg) \\ Jaume Garau (Universitat dels Illes Ballears) \\ Luis Gómez Canseco (Universidad de Huelva) \\ Valle Ojeda Calvo (Università Ca’ Foscari) \\ Victoria Pineda (Universidad de Extremadura) \\ Yolanda Rodríguez Pérez (Universiteit van Amsterdam) \\ Pedro Ruiz Pérez (Universidad de Córdoba) \\ Alexander Samson (University College London) \\ Germán Vega García-Luengos (Universidad de Valladolid) \\ María José Vega Ramos (Universitat Autònoma de Barcelona)
}




\title{
La conversación civil
}

\section{Esteban Guazzo}

\author{
Traducida por \\ don Joseph Gerardo de Hervás
}

Edición crítica, introducción y notas de

Giuseppe Marino

Estudio preliminar de

Jesús Gómez

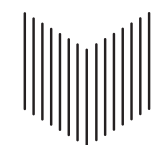

Iberoamericana - Vervuert

Madrid - Frankfurt

2019 
Esta edición ha sido financiada con una ayuda concedida por el College of Foreign Language and Literature al Departamento de Estudios Hispánicos de la Fudan University, Shanghái.

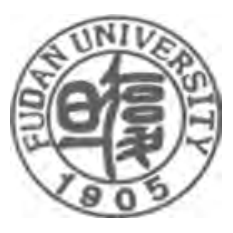

Cualquier forma de reproducción, distribución, comunicación pública o transformación de esta obra solo puede ser realizada con la autorización de sus titulares, salvo excepción prevista por la ley. Diríjase a CEDRO (Centro Español de Derechos Reprográficos) si necesita fotocopiar o escanear algún fragmento de esta obra (www.conlicencia.com;

$917021970 / 932720447)$.

\section{Derechos reservados}

(C) Iberoamericana, 2019

Amor de Dios, 1 - E-28014 Madrid

Tel.: +34914293522 - Fax: +34914295397

(C) Vervuert, 2019

Elisabethenstr. 3-9 - D-60594 Frankfurt am Main

Tel.: +49695974617 - Fax: +49695978743

info@iberoamericanalibros.com

www.iberoamericana-vervuert.es

ISBN 978-84-9192-026-7 (Iberoamericana)

ISBN 978-3-95487-951-9 (Vervuert)

ISBN 978-3-95487-952-6 (e-book)

Depósito Legal: M-1174-2019

Diseño de la cubierta: Rubén Salgueiros

Imagen de cubierta: retrato de Vespasiano I Gonzaga, atribuido a Bernardino Campi, c. 1582.

Impreso en España

Este libro está impreso íntegramente en papel ecológico sin cloro. 
